\begin{tabular}{|c|l|}
\hline Title & Surface Heat Bal ance and Spatially Distributed A blation Modelling at Koryto Glacier, Kamchatka Peninsula, Russia \\
\hline Author(s) & Konya, Keiko; Matsumoto, Takane; Naruse, Renji \\
\hline Citation & $\begin{array}{l}\text { Geografiska A nnaler: Series A, Physical Geography, 86(4), 337-348 } \\
\text { https://doi.org/40.1111/.0435-3676.2004.00236.X }\end{array}$ \\
\hline Issue Date & 2004 12 \\
\hline Doc URL & http://hdl.handle.net/2115/4872 \\
\hline Type & article (author version) \\
\hline File Information & GA SA 86A-4.pdf \\
\hline
\end{tabular}

Instructions for use 


\section{Surface heat balance and spatially distributed ablation modeling at Koryto Glacier, Kamchatka Peninsula, Russia}

Keiko KONYA ${ }^{1,2}$, Takane MATSUMOTO ${ }^{2 *}$, Renji NARUSE ${ }^{2}$

1. Graduate School of Environmental Earth Science, Hokkaido University, Sapporo 060-0810, Japan

2. Institute of Low Temperature Science, Hokkaido University, Sapporo 060-0819, Japan

* Present address: Division of Earth and Planetary Sciences, Graduate School of Science, Hokkaido University, Kita 10, Nishi 8, Kita-ku, Sapporo 060-0810, JAPAN

Corresponding author: Keiko KONYA

Tel: +81-11-706-5476; Fax: +81-11-706-7142

E-mail address: konya@lowtem.hokudai.ac.jp

Konya, K., Matsumoto, T. and Naruse, R., 200*: Surface heat balance and spatially distributed ablation modeling at Koryto Glacier, Kamchatka Peninsula, Russia. Geogr. Ann., **: **_**. 


\section{Abstract}

To investigate the characteristics of ablation at Koryto Glacier, a mountain glacier under maritime climate in Kamchatka Peninsula, Russia, we made field observations from August to early September, 2000. At a site near the equilibrium line, the 31-day average net radiation, sensible heat flux, and latent heat flux were 43,59 , and $31 \mathrm{~W} \mathrm{~m}^{-2}$, respectively. We developed a new distributed ablation model, which only needs measurements of air temperature and global radiation at one site. Hourly ablation rates at this site obtained by the energy balance method are related to measured air temperature and global radiation by linear multiple regression. A different set of multiple regression coefficients is fitted for snow and ice surfaces. Better estimates of ablation rate can be obtained by this approach than other temperature index models. These equations are then applied to each grid cell of a digital elevation model to estimate spatially distributed hourly melt. Air temperature is extrapolated using a constant temperature lapse rate and global radiation is distributed considering topographic effects. The model enables us to calculate the hourly spatial distribution of ablation rates within the glacier area and could well provide a realistic simulation of ablation over the whole glacier.

Key words: maritime glacier, heat balance, distributed ablation model, Koryto Glacier, Kamchatka Peninsula 


\section{Introduction}

Reliable estimates of mass balance, interactions with climate, and the hydrological regime of a glacier require an accurate determination of ablation. For a period longer than one day, a reasonable estimate of the ablation on the whole glacier can be obtained using the degree-day method, provided that it includes the change in daily mean air temperature with elevation (e.g., Laumann and Reeh, 1993; Braithwaite and Zhang, 2000). Such an approach has been widely used in glacier studies; for example, to estimate the summer mass balance and net balance. However, in practice, the ablation rate on a glacier surface is likely to have a complicated spatial distribution due to the shading effect from surrounding slopes and the local circulation of air caused by the difference in surface conditions around the glacier. Furthermore, spatial variations in local climatic factors show up in the time scale of less than one day. Thus, one should include the time-dependent spatial distribution of ablation rate when analyzing phenomena that are affected by short-term variations in meltwater flux, such as runoff from the glacier and the influence of subglacial water flow on glacial motion.

In order to take account of the time-dependent spatial variation of ablation, distributed ablation models have been recently developed for some glaciers. Also in the field of snow hydrology, snowmelt from mountainous basins has been computed to detect the discharge of the basin using distributed ablation models (e.g. Kustas et al., 1994; Cazorzi and Dalla Fontana, 1996; Kane et al., 1997).

There are two types of ablation models. The first contains physically-based distributed models that use the laws of heat exchange processes and solutions to the heat balance equations for snow and ice. For example, to calculate ablation at Haut Glacier d'Arolla, Switzerland, Arnold et al. (1996) used a model based on simplified heat balance equations. Later Brock et al. (2000) used the same model to examine how the spatial and temporal patterns of surface heat balance depend on albedos and 
aerodynamic roughness lengths that are both nonuniform and non-constant. Other distributed models with a physical approach have been developed by Escher-Vetter (2000), Willis et al. (2002), and Klok and Oerlemans (2003). Ideally, these models can be adapted to any glacier because they scarcely include empirical factors. However, they need as input many meteorological variables that are difficult to collect for most glaciers. Therefore, in practice, this type of model is applicable for a limited period on relatively few glaciers.

The second, as already reviewed by Hock (2003) more pragmatic approach considers the meteorological variables as indices of physical processes. The temperature index model, better known as the degree-day method, is typical of this category. Some distributed models that have been developed for mountain glaciers and snowy basins are based on the temperature index and include a distribution of radiative energy flux into the surface. For example, Kustas et al. (1994) used a model that combines the temperature index with a simplified radiation balance, and Cazorzi and Dalla Fontana (1996) used a model with a distributed radiation index that was calculated from a digital elevation model (DEM). However, outputs of these models were daily ablation rates within snowy basins. In addition, Hock (1999) proposed a model that predicts the distribution of hourly ablation rates on Storglaciären, Sweden. The model by Hock (1999) uses a temperature index combined with the potential clear-sky direct solar radiation. The model considerably improved the simulation of diurnal discharge fluctuations of proglacial streams and yielded a more realistic spatial distribution of ablation rates. Models using this second type of approach are applicable to many glaciers, provided that some meteorological data are available; however, in practice, some of the coefficients will need tuning.

In this paper, we first describe the results of meteorological observations on Koryto Glacier, a maritime mountain glacier in Kamchatka Peninsula, Russia in the summer of 2000. We use these measurements to clarify the heat balance characteristics on the 
surface of the glacier. Then, we use air temperature and global radiation data as model inputs for a new distributed ablation model based on an empirical approach that can estimate hourly changes in the spatial distribution of ablation rate. Then we evaluate this model for use on Koryto Glacier by comparing with the other models such as the Hock model, which represents a typical empirical model, and validate whether our model describes ablation rate realistically or not.

\section{Site description}

Koryto Glacier is located at the Kronotsky Peninsula on the eastern coast of Kamchatka Peninsula in the Russian Far East (Fig. 1). The glacier is 7-km long and has an area of $7.8 \mathrm{~km}^{2}$, flowing towards the northwest from $1200 \mathrm{~m}$ a.s.l. to the terminus at $300 \mathrm{~m}$ a.s.1. The surface of the glacier is relatively flat $\left(<15^{\circ}\right)$ except the area around the glacier tongue, and is not covered with debris. Among the 32 glaciers on the Kronotsky Peninsula whose ELAs are lower than 1000 m a.s.1., Koryto Glacier is one of the largest. According to IAHS/UNEP/UNESCO (1988), the ELA of the glacier in the balance year 1981/ 82 was at $780 \mathrm{~m}$ a.s.1.

At Koryto Glacier, glaciological observations have been conducted intermittently since 1960 by Russian scientists. Also, a joint Russo-Japanese research project was carried out in the summers of 1996, 1997, and 2000. Results are presented by Kodama et al. (1997) on preliminary observations of meteorological conditions and heat balance, also by Yamaguchi et al. (2003) on the glacier dynamics, and by Matsumoto et al. (2004) on the water balance of the glacier based on observations from 2000, respectively.

The glaciers on the eastern coast of Kamchatka including Koryto Glacier are subject to extreme maritime climatic conditions, namely heavy snowfall in winter and large 
ablation in summer. According to the measurements at an automatic weather station set up on the bare ground at the uppermost ridge (RID in Fig. 1) in 1996/97 (Matsumoto et al., 1997), the maximum and minimum monthly mean air temperature was $9.8^{\circ} \mathrm{C}$ in August 1996 and $-13.6{ }^{\circ} \mathrm{C}$ in February 1997, respectively. According to Dyurgerov and Meier (1999), the 13-year-average, annual mass balance amplitude of this glacier is estimated as $3.54 \mathrm{~m}$ w.e., which is the second largest value among those of 50 glaciers in the northern hemisphere.

\section{Field observations}

\section{Methods of observations}

Meteorological and glaciological observations for this study were done at Koryto Glacier from 7 August to 12 September 2000. We installed a meteorological station at site KK1, near the ELA at $810 \mathrm{~m}$ a.s.l. (Fig. 1). During the observation period, the following variables (type of sensor; height from the ground) were measured and recorded continuously at 1-hour intervals: global radiation (PCM-01, Prede; $155 \mathrm{~cm}$ ), net radiation (MF-11, EKO Instruments Trading; $155 \mathrm{~cm}$ ), air temperature and relative humidity (HMP45A, Vaisala or TR-71S, T\&D; $175 \mathrm{~cm}$ ), wind direction and speed (model 05701, Young; $200 \mathrm{~cm}$ ), surface temperature (IT-340, Horiba; $60 \mathrm{~cm}$ ), and atmospheric pressure (PTB220, Vaisala; $5 \mathrm{~cm}$ ). These instruments were installed on a mast and we adjusted instrument heights after surface lowering due to melting. Air temperature sensors were covered with plastic shelters that ventilated naturally. The thermometers were calibrated with $0^{\circ} \mathrm{C}$ water and an Assmann aspiration psychrometer. Relative humidity sensors were calibrated with saturated humidity of $\mathrm{NaOH}$ and $\mathrm{CaCl}_{2}$, respectively. We used measurements by the automatic weather station at RID (period of the measurement: 12 August 1999 to 3 September 2000) and established relationships 
between measurements at RID and KK1 to fill gaps in the data record at KK1.

In addition, at the eight sites $\mathrm{KK} 0$ to $\mathrm{KK} 7$, the air temperatures were measured and recorded at 1-hour intervals. We also obtained the daily ablation rates at the eight sites by measuring changes in stake height nearly every day. Density of the snowpack at each stake was measured several times through the observation period. The density of ice was assumed to be $900 \mathrm{~kg} \mathrm{~m}^{-3}$.

Albedo was measured seven times at KK1 and fewer times at other ablation stakes during the observation period. At KK1, the condensation was measured 16 times by measuring changes in weight of a plastic dish (19 cm long, $13 \mathrm{~cm}$ wide, and $3 \mathrm{~cm}$ deep) filled with snow whose surface condition was preserved. Furthermore, to estimate the initial distribution of snow water equivalent (SWE) of the last two winters, we drilled into the snowpack to obtain core samples at KK0 and KK1 on 4 and 5 August.

\section{Results of observations}

The daily ablation rate and hourly weather conditions at KK1 during the observation period are shown in Figure 2. The ablation rate seems to fluctuate in phase with the air temperature. It was high (around $60 \mathrm{~mm}$ w.e. $\mathrm{d}^{-1}$ ) in early August and September and low $\left(<20 \mathrm{~mm}\right.$ w.e. $\left.\mathrm{d}^{-1}\right)$ in late August. Air temperature varied between 4 and $10^{\circ} \mathrm{C}$ in August and exceeded $20^{\circ} \mathrm{C}$ on a day in early September. The mean daily air temperature during the observation period was $7.6^{\circ} \mathrm{C}$. Also, the temperature lapse rate on the glacier was obtained from mean air temperatures at six sites as $7.6{ }^{\circ} \mathrm{C} \mathrm{km}^{-1}$. Moreover, the positive degree-day factor, which is defined as the cumulative ablation divided by the cumulative daily mean air temperature, was determined as $4.7 \mathrm{~mm}$ w.e. ${ }^{\circ} \mathrm{C}^{-1} \mathrm{~d}^{-1}$ for the snow surface and $7.0 \mathrm{~mm}$ w.e. ${ }^{\circ} \mathrm{C}^{-1} \mathrm{~d}^{-1}$ for the ice surface.

The vapor pressure was higher than the saturation vapor pressure of ice at $0{ }^{\circ} \mathrm{C}(6.11$ $\mathrm{hPa}$ ) on almost all days during the observation period. In early August, it was often rainy or cloudy; the global radiation was smaller than that on other days. The mean 
global and net radiation during the observation period were 149 and $38 \mathrm{~W} \mathrm{~m} \mathrm{~m}^{-2}$, respectively. Net radiation was almost zero and sometimes negative at night. The prevailing wind direction at KK1 was southeasterly, particularly in mid-August, which is the same as the glacial flow direction. The wind speed was weak $\left(2.4 \mathrm{~m} \mathrm{~s}^{-1}\right.$ on average) and fluctuates in phase with the general trends in air temperature. These features imply that a glacier wind tends to develop on this glacier in summer.

Measured albedos of the snow surface at KK1 ranged from 0.59 to 0.68 , and ice albedo in the ablation area varied between 0.09 and 0.26 . The density of surface snow at $\mathrm{KK} 1$, as measured at midday, varied between 520 and $640 \mathrm{~kg} \mathrm{~m}^{-3}$, and was $580 \mathrm{kgm}^{-3}$ on average. Based on 16 measurements, the average condensation rate was $0.9 \times 10^{-2}$ $\mathrm{mm}$ w.e. $\mathrm{h}^{-1}$. From a drilled core sample, we obtained that $1.72 \mathrm{~m}$ w.e. last winter snow was left at KK1 on August 4.

\section{Surface heat balance}

\section{Computation}

To understand the ablation of the glacier, we calculate and discuss the surface heat balance at KK1 during the observation period. The heat balance on a temperate melting glacier surface is

$$
Q_{M}=Q_{R}+Q_{H}+Q_{E}
$$

where $Q_{M}$ is the heat flux used for melting, $Q_{R}$ the net radiation, $Q_{H}$ the sensible heat flux, and $Q_{E}$ the latent heat flux for condensation/evaporation. The flux towards the surface is defined as positive. The precipitation heat flux and the conductive heat flux below the surface are disregarded here. The turbulent heat fluxes $Q_{H}$ and $Q_{E}$ are 
calculated using a bulk aerodynamic approach:

$$
\begin{aligned}
& Q_{H}=k_{H} \rho C p u\left(T-T_{0}\right), \\
& Q_{E}=k_{E} \rho l(0.622 / P) u\left(e-e_{0}\right),
\end{aligned}
$$

where $k_{H}$ and $k_{E}$ are the bulk exchange coefficients for the sensible and the latent heat fluxes, $\rho$ the air density , $C p$ the specific heat of air at constant pressure, $u$ the wind speed , $T$ the air temperature, $T_{0}$ the surface temperature, $l$ the latent heat of vaporization of water, $P$ the atmospheric pressure, and $e$ and $e_{0}$ the vapor pressures at the sensor height and at the surface. In this study, we assume neutral conditions, and decided the coefficients to be best fitted to measured condensation rates and other meteorological conditions, assumed $k_{H}=k_{E}=2.7 \times 10^{-3}$ (no dimension). Although we did not take account for stability in these calculation, we believe that the calculation is enough reasonable because ablation rates calculated using Eqs. (1), (2) and (3) well agree with those measured by the stake method as shown later.

\section{Characteristics at KK1}

Variations in the daily amount of the net radiation, the sensible heat flux, and the latent heat flux during the observation period are shown in Figure 3. The resulting calculated ablation agrees well with the measured ablation by stakes (Fig. 4).

The proportions of these fluxes to the total heat source for ablation are roughly constant from 15 to 23 August, whereas the sensible heat flux is quite large in early September due to the high air temperature. The daily latent heat flux is always positive indicating condensation and, on many of the days, its contribution is as large as that of the net radiation. Although there is a large amount of global radiation in mid-August, the amount of net radiation is small. This might have been caused by a large negative 
net longwave radiation due to clear weather. Over the observation period, the average daily values of net radiation, sensible heat flux, and latent heat flux were 43,59 , and 31 $\mathrm{W} \mathrm{m} \mathrm{m}^{-2}$, corresponding to $33 \%, 44 \%$, and $23 \%$ of the total heat for ablation, respectively.

Such a high proportion of turbulent heat flux was obtained at Koryto Glacier in 1976 (Table. 1). Large contributions of the sensible and the latent heat fluxes for ablation in summer have also been observed at other maritime glaciers. These results indicate that large contributions of the turbulent heat fluxes, particularly the latent heat flux, can be regarded as a typical feature of heat balance on maritime glaciers including Koryto Glacier.

\section{Distributed radiation and temperature index model}

\section{Construction of ablation model}

To estimate the spatial variation in ablation rate on Koryto Glacier using air temperature and global radiation, we propose a distributed ablation model with a simple form, "distributed radiation and temperature index model" (hereafter referred to as The RT model) in this study. The model includes spatial variations in air temperature and global radiation that have commonly been used in other distributed models (e.g., Williams and Tarboton, 1999) to estimate the distribution of ablation rate. We assume that the hourly ablation rate $M(\mathrm{~mm}$ w.e. $)$ at a given site is

$$
M=\alpha R+\beta T+\gamma
$$

where $R$ is the global radiation $\left(\mathrm{W} \mathrm{m}^{-2}\right)$ and $T$ is the air temperature $\left({ }^{\circ} \mathrm{C}\right)$ at the site. Coefficients $\alpha, \beta$, and $\gamma$ are empirically determined by multiple regression to best fit to the measured $M$. We determine one set of these coefficients to describe a surface 
condition of snow and another set for cases in which the surface is ice. To obtain the coefficients for a snow surface, we did the multiple regression analysis using the following data from KK1: the global radiation, air temperature, and the hourly ablation rate calculated by the heat balance method. Since the surface of KK1 was covered with snow through the observation period, we needed to derive the regression coefficients over an ice surface in an alternative way. Meteorological variables, except for air temperature, were not obtained on ice surface. Thus, we used the heat balance method to estimate hourly ablation rate by collecting a dataset at KK4 (570 m a.s.1.) as follows. The measured albedo at KK4 on the ice surface was used; the air temperature and atmospheric pressure were extrapolated from those at KK1; the relative humidity, wind speed, global radiation, and the incoming longwave radiation, which was estimated from net radiation, global radiation and albedo, were assumed to be the same as those at KK1. Also, the bulk coefficients $k_{H}$ and $k_{E}$ were assumed to equal those at KK1 $(2.7 \mathrm{x}$ $10^{-3}$ ) because the calculated ablation rate using these values could accurately simulate the measured ablation rate at KK4. The equations we determined by the method mentioned above are

$$
M_{\text {snow }}=0.42 R+0.089 T-0.28 \text {, }
$$

and

$$
M_{\text {ice }}=0.83 R+0.072 T-0.21 \text {. }
$$

When the calculated $\mathrm{M}$ becomes negative, we assume that $\mathrm{M}_{\text {snow/ice }}=0$.

Figure 5a compares the temporal variation in ablation rate at $\mathrm{KK} 1$ calculated by Equation (5) with that from the heat balance method. This model can simulate well the diurnal variation in ablation from hourly air temperature and global radiation. The coefficient of detemination between the estimates by these two methods is $r^{2}=0.77$ for 
KK1 and 0.88 for KK4.

\section{Estimating the distribution of ablation}

To estimate the ablation distribution, we use Eqs.(5) and (6) at each gridcell of a DEM of the glacier surface with 50-m resolution using GIS (ArcView 3.2, ESRI). The DEM was developed from the 1960 map of the glacier. Although the glacier has retreated by $450 \mathrm{~m}$ and thinned by 20-40 m between 1960 and 2000 (Yamaguchi et al., 2003), we ignored such changes because they are unlikely to significantly affect the model results. The resolution of gridcells in this study is slightly coarser than those in other distributed ablation models (Escher-Vetter, 1985; Arnold et al., 1996; Hock, 1999; Brock et al., 2000); however, we consider that 50-m gridcells are sufficient because the glacier is relatively flat and the original map does not have a significantly higher resolution.

We estimated model inputs $T$ and $R$, and the initial SWE at each gridcell as follows. The distribution of air temperature is simply regarded as a function of altitude and is calculated using the measured $T$ at $\mathrm{KK} 1$, the lapse rate averaged for the entire glacier through the observation period, and the altitude of each gridcell. The incoming shortwave radiation was estimated using measured $R$ at $\mathrm{KK} 1$, and the potential direct solar radiation $I\left(\mathrm{~W} \mathrm{~m}^{-2}\right)$ was calculated using a program prepared by Ishikawa (2001) that include the sun's position and local slope. To include atmospheric transmissivity and cloudiness, we calculated the ratio of the measured global radiation to the potential direct solar radiation at KK1 in every time step:

$$
\zeta=R_{(\mathrm{KK} 1)} / I_{(\mathrm{KK} 1)}
$$

Assuming that $\zeta$ is uniform over the entire glacier, we multiply this value by $I$ at a given gridcell $i$ to estimate the global radiation at the gridcell: 


$$
R_{(\mathrm{i})}=\zeta I_{(\mathrm{i})}
$$

Incoming shortwave radiation is assumed zero at shaded gridcells although there is diffuse radiation. As mentioned in Hock and Noetzli (1997), an explicit separation of global radiation into direct and diffusive components was not applied.

As can be seen in Figure 6, the shaded area clearly exhibits diurnal variation in their spatial distribution. In the morning, the surrounding topography shades the area near the terminus and the accumulation area (a). Because the solar altitude is high in summer in this latitude, the global radiation has a nearly uniform distribution over the whole glacier at midday (b). In the evening, the surrounding ridges shade the southern part of the glacier (c).

The distinction between snow and ice at each gridcell is made at every time step from the initial SWE and the cumulative amount of ablation. The distribution of the initial SWE is assumed to be a linear function of altitude that was obtained from the SWE at $\mathrm{KK} 0$ and $\mathrm{KK} 1$ in the beginning of the observation period. When the cumulative ablation exceeds the initial SWE at a gridcell, Equation (6) is used instead of Equation (5).

\section{Model calculation}

The modeled spatial distribution of the cumulative ablation on Koryto Glacier from 8 August to 10 September is shown in Figure 7. In general, the cumulative ablation decreases with an increase in altitude, due to a decrease in air temperature with elevation; however, differences in ablation can be found among localities at the same altitude, especially between the area around the central flow line and the lateral margins. Ablation tends to be smaller near the lateral margins. The transverse profile of ablation along the two lines, a-b and c-d, are shown in Figures $7 \mathrm{~b}$ and $7 \mathrm{c}$, respectively. Ablation near the margin of the line a-b are nearly the same, although the altitude of site a is 
much lower than that of site b. This is due to the effect of the surrounding topography in shading from solar radiation. The profile along the line c-d shows a less remarkable effect of shading than that of a-b.

\section{Discussion}

\section{Validation of the model}

To evaluate the RT model, here we compare the result of simulation on the temporal variation in the total ablation rate over the entire glacier by the RT model and those by two other methods, namely the degree-day method and the heat balance method based on the simplest assumption on the distribution of meteorological elements. Calculations by the heat balance method and the degree-day method were made for each $100-\mathrm{m}$ elevation interval of the glacier area and gave specific ablation on the glacier. Using the degree-day method, mean ablation rate within an elevation interval can be expressed as follows:

$$
M=F_{d d}\left(T_{\mathrm{KK} 1}+\Gamma \Delta h\right)
$$

where $F_{d d}$ is the degree-day factor, $\Gamma$ is the temperature lapse rate and $\Delta h$ is difference in altitude between KK1 and the median height of a elevation interval. On the other hand, the heat balance calculation was made by Eqs. (1), (2) and (3) based on the following assumptions: longwave radiation is constant over the glacier; observed albedo at each stake represents the vicinity; wind speed, relative humidity and bulk exchange coefficients are the same over the glaciated area; air temperature and atmospheric pressure decrease with the altitude.

The result of the comparison is shown in Figure 8. The estimate by the degree-day 
method is significantly lower than that by the heat balance method in mid-August. The RT model is possible to simulate the rapid daily changes in the beginning and the end of August and the beginning of September, but the degree-day method is unable. These results indicate that the RT model yields estimates of total ablation that is more accurate than those by the degree-day method and similar to the heat balance.

However, there are some problems remained in the RT model. First, the snowline retreat simulated with the RT model was slower than the measured retreat for the observation period. This might be caused by an uncertainty in the estimation of the initial SWE. We estimated the winter balance assuming that its gradient in 1998/99 was equal to that in 1999/00. However, the winter balance may change from year to year, and the estimated initial SWE used in this calculation might be an overestimate. In fact, the annual mass balance in 1999/00 was negative. Second, there is uncertainty in validation of ablation rate because of lack of data. Since the ablation stakes are set along the centerline, which is seldom in shade, stake measurement data do not sufficiently show the shading effect on ablation rate.

\section{Model evaluation}

There are differences in variables and also in forms of the formulas between the RT model and other distributed temperature index models. For example, the model established for Storglaciären by Hock (1999) can be expressed as follows:

$$
M=(\alpha I+\beta) T
$$

and is applicable to more easily available inputs such as daily mean air temperature and potential clear-sky direct solar radiation $(I)$. Therefore, we try to examine how the differences in inputs and formulas can affect the accuracy of estimation of ablation rate at KK1 during the observation period. For that purpose, four combinations of inputs $(T$ : 
hourly air temperature or daily mean air temperature, $R$ : measured global radiation or $I$ : potential direct solar radiation) were put into the RT model (Eq. 5) and the Hock model (Eq. 10). The two coefficients in Eq. (5) and (10) were determined as the best-fit in each combination of inputs. Then we calculated the coefficient of determination $\left(r^{2}\right)$ of the relationship, and the residual sum of squares (RSS) from the hourly ablation rate obtained by the heat balance method.

The summary of the results is shown in Table 2. Time series of the ablation rates estimated by the RT model with hourly temperature and measured radiation, and by the Hock model with the same inputs are also shown in Figure 5. Clearly, Table 2 shows that the RT model with hourly temperature and measured radiation could obtain the best estimate among the eight cases $\left(r^{2}=0.77\right.$ and RSS $=115 \mathrm{~mm}$ w.e. $)$. The Hock model with the same inputs could also obtain the good estimate, however, it overestimated the ablation rate in the periods of high ablation rates with the large contribution of the turbulent heat fluxes (e.g. mid-August and early September) and of quite low ablation rate around zero. This may suggest that the RT model is slightly more suitable for simulation of ablation rate at maritime glaciers than the Hock model. Anyway, these results show that the difference in the type of formulas should not have so large influence on simulation. On the other hand, it is clear from Table 2 that the use of measured global radiation instead of the potential direct solar radiation strongly improves the estimation. We consider that the term of radiation is the most significant factor for estimation of ablation rate by the RT model. Difference between hourly and daily temperatures, in contrast, should not be significant.

Because the magnitude of the radiation term in Equations (5) and (6) becomes much larger than other terms especially in daytime, the variation in global radiation should be regarded as the controlling factor for temporal variation in ablation rate, though the contribution of turbulent heat fluxes is quite large on this glacier. This suggests that the RT model can simulate ablation rates better at glaciers where the contribution of the net 
radiation for ablation is much larger. Moreover, the effect on ablation by shading from the surrounding topography can be much larger for glaciers surrounded by higher and steeper slopes or at high latitudes, whereas such an effect is limited to relatively small areas near the sidewalls at Koryto Glacier. Thus, this suggests that the RT model should be useful for mountain glaciers, especially those surrounded by steep slopes or at high latitudes.

\section{Conclusions}

To evaluate spatial variations with high time resolution in ablation rate from a few components of meteorological variables, the RT model, a new distributed ablation model was constructed for Koryto Glacier where the contribution of the turbulent heat fluxes for ablation is large under the maritime climate. This model consists of the temperature index combined with the distribution of global radiation on the surface. Two equations for snow and ice surfaces were determined by multiple regressions to best fit to the hourly ablation rates at KK1 and KK4 obtained by the heat balance method. At each 50-m gridcell on the glacier surface, the hourly air temperature and global radiation were estimated from measured values at KK1 and DEM, and then the ablation rate at the gridcell was calculated with the regression equation using GIS. The RT model can simulate the variation in hourly ablation rates, and also the spatial difference in ablation rates within the area of the same altitude. Thus, this model may bring a better simulation of daily water input by ablation over the whole glacier than the other simpler models such as the degree-day method. Even though wind speed is supposed to be an inevitable factor to calculate ablation rates, here we succeeded in computing the ablation rate on the glacier only with radiation and temperature. 
However, since we did not have enough data to verify this model calculation, the model needs to be validated on another glacier with spatially distributed ablation data. The validated data such as ablation rate and heat balance calculation at many points would give a good solution for the problem.

\section{Acknowledgments}

We express our gratitude to Y. D. Muravyev of the Russian Academy of Sciences, T. Yamada of the Institute of Low Temperature Science, T. Aoki of Kanazawa University, S. Yamaguchi of the National Research Institute for Earth Science and Disaster Prevention, S. Sugiyama of the Swiss Federal Institute of Technology, and all other members of the Joint Russo-Japanese Research Project at Koryto Glacier in 2000 for their help on the observations and logistical supports in the field. Gratitude also goes to M. Ishikawa of the Japan Marine Science and Technology Center for providing us with his program for GIS. Precise comments and suggestions from Regine Hock and an anonymous reviewer led to major improvements in the manuscript. This study was supported by a Grant-in-Aid of the Ministry of Education, Science, Sports and Culture of Japan (No. 11691166).

\section{References}

Arnold, N. S., Willis, I. C., Sharp, M. J., Richards, K. S. and Lawson, W. J., 1996: A distributed surface energy-balance model for a small valley glacier. I. Development and testing for Haut Glacier d'Arolla, Valais, Switzerland. Journal of Glaciology, 42: 77-89. 
Braithwaite, R. J. and Zhang, Y., 2000: Sensitivity of mass balance of five Swiss glaciers to temperature changes assessed by tuning a degree-day model. Journal of Glaciology, 46: 7-14.

Brock, B. W., Willis, I. C., Sharp, M. J. and Arnold, N. S., 2000: Modelling seasonal and spatial variations in the surface energy balance of Haut Glacier d'Arolla, Switzerland. Annals of Glaciology, 31: 53-62.

Cazorzi, F. and Dalla Fontana, G., 1996: Snowmelt modeling by combining air temperature and a distributed radiation index. Journal of Hydrology, 181: 169-187.

Dyurgerov, M. B. and Meier, M. F., 1999: Analysis of winter and summer glacier mass balance. Geografiska Annaler, 81A: 541-554.

Escher-Vetter, H., 2000: Modelling meltwater production with a distributed energy balance method and runoff using a linear reservoir approach - results from Vernagtferner, Oetztal Alps, for the ablation seasons 1992 to 1995. Zeitschrift fur Gletscherkunde und Glazialgeologie, 36: 119-150.

Hock, R., and Noetzli, C., 1997: Areal melt and discharge modelling of Storglaciären, Sweden. Annals of Glaciology, 24: 211-216.

Hock, R., 1999: A distributed temperature-index ice- and snowmelt model including potential direct solar radiation. Journal of Glaciology, 45: 101-111.

Hock, R., 2003: Temperature index melt modelling in mountain regions. Journal of Hydrology, 282 (1-4): 104-115.

IAHA/UNEP/UNESCO, 1988: Fluctuations of Glacier 1980-1985. Vol. V. World Glacier Monitoring Service. Zurich. 290 p.

Ishikawa, N., Owens, I. F. and Sturman, A. P., 1992: Heat balance characteristics during fine periods on the lower parts of the Franz Josef Glacier, South Westland, New Zealand, International Journal of Climatology, 12: 397-410.

Ishikawa, M., 2001: Distribution of mountain permafrost in the Daisetsu Mountains, 
Hokkaido Northern Japan. Ph D-thesis, Graduate School of Environmental Earth Science, Hokkaido University. 123 p.

Jansson, P., R. Hock., T. Scheneider, 2002: The concept of glacier storage - a review. Journal of Hydrology, 282, 116-129.

Kane, D., Gieck, R. E., and Hinzman, L.D., 1997: Snowmelt Modeling at Small Alaskan Arctic Watershed. Journal of Hydrologic Engineering, 2(4), 204-210.

Klok, E. J. and Oerlemans, J., 2003: Model study of the spatial distribution of the energy and mass balance of Morteratschgletscher, Switzerland. Journal of Glaciology, 48: 505-518.

Kobayashi, S. and Saito, T., 1985: Heat balance on Soler Glacier. In: Nakajima, C. (ed.): Glaciological studies in Patagonia Northern Icefield, 1983-1984. Data Center for Glacier Research, Japanese Society of Snow and Ice. (133 p): 46-51.

Kodama, Y., Matsumoto, T., Glazirin, G. E., Muravyev, Y. D., Shiraiwa, T. and Yamaguchi, S., 1997: Hydrometeorological features of Koryto glacier in the Kronotsky Peninsula, Kamchatka, Russia. Bulletin of Glacier Research, 15: 37-45. Kustas, W. P., Rango, A. and Uijlenhoet, R., 1994: A simple energy budget algorithm for the snowmelt runoff model. Water Resources Research, 30: 1515-1527.

Laumann, T. and Reeh, N., 1993: Sensitivity to climate change of the mass balance of glaciers in southern Norway. Journal of Glaciology, 39: 656-665.

Markin, V. A., 1976: Specific features of heat supply to the surface of glaciers of Kamchatka in ablation season. Glaciological Research, 25: 27-35. (in Russian with English abstract)

Matsumoto, T., Kodama, Y., Shiraiwa, T., Yamaguchi, S., Sone, T., Nishimura, K., Muravyev, Y. D., Khomentovsky, P. A. and Yamagata, K., 1997: Meteorological observations by Automatic Weather Stations (AWS) in alpine regions of Kamchatka, Russia, 1996-1997. Low Temperature Science, Ser. A., 56 Data Report: 53-68. 
Matsumoto, T., Naruse, R., Konya, K., Yamaguchi, S., Yamada T. and Muravyev, Y. D. 2004: Summer water balance characteristics of Koryto Glacier, Kamchatka Peninsula, Russia. Geografiska Annaler, 86A: 1681-190.

Shiraiwa, T., Muravyev, Y. D., Yamaguchi, S., Glazirin, G. E., Kodama, Y. and Matsumoto, T., 1997: Glaciological features of Koryto Glacier in the Kronotsky Peninsula, Kamchatka, Russia. Bulletin of Glacier Research, 15: 27-36.

Streten, N. A. and Wendler, G., 1968: The midsummer heat balance of an Alaskan maritime glacier. Journal of Glaciology, 7: 431-440.

Williams, K. S., and Tarboton, D. G., 1999: The ABC's of snowmelt: a topographically factorized energy component snowmelt model. Hydrological Processes, 13: 1905-1920.

Willis, I. C., Arnold, N. S. and Brock, B. W., 2002: Effect of snowpack removal on energy balance, melt and runoff in a small supraglacial catchment. Hydrological Processes, 16: 2721-2749.

Yamaguchi, S., Naruse, R., Sugiyama, S., Matsumoto, T. and Muravyev, Y. D., 2003: Initial investigation on dynamics of the maritime Koryto Glacier, Kamchatka, Russia. Journal of Glaciology, 49: 173-178. 


\section{Figure Captions}

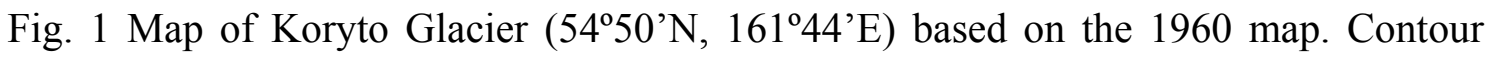
lines are drawn with $20 \mathrm{~m}$ spacing. Elevation of the glacier surface in the original map was revised based on the GPS survey in 2000, whereas the retreat of the terminus is disregarded in this map. Open circles indicate the sites with ablation stakes and solid circles show the meteorological stations.

Fig. 2 Meteorological data and measured daily ablation rates obtained at KK1 from 6 August to 12 September 2000. Dotted lines in the columns of global and net radiations indicate values estimated using the data measured at the RID. The horizontal dashed line in the vapor pressure marks the saturation vapor pressure of ice at $0{ }^{\circ} \mathrm{C}(6.11 \mathrm{hPa})$. The surface at $\mathrm{KK} 1$ is snow throughout the period.

Fig. 3 Daily heat balance components at the snow surface at KK1.

Fig. 4 The relationship between daily ablation calculated by the heat balance method and that measured by the stake method. Standard deviation of errors is also shown in the figure.

Fig. 5 Temporal variations in hourly heat source for ablation at KK1 calculated by the RT model using hourly air temperature and measured global radiation as inputs (a) and that by the ablation model by Hock (1999) using hourly air temperature and measured global radiation as inputs (b). Dotted lines in both figures indicate hourly heat source calculated by the heat balance method.

Fig. 6 Spatial variation in shading on Koryto Glacier at 7:00 (a), 14:00 (b) and 20:00 (c) on August 8, 2000. Black parts indicate shaded areas $(I=0)$ and white parts are areas in the sun $(I>0)$.

Fig. 7 Distribution of the total ablation from August 8 to September 10, 2000 (a). Transverse profiles in the total ablation along the lines $a-b$, and c-d are shown in (b) and (c), respectively. 
Fig. 8 Comparison between the total daily ablation rates within the entire glacier calculated with the RT model (thick line), the degree-day method (dotted line), and the heat balance method (shaded bars).

Table 1 The summary of the contribution of each heat balance component for ablation on Koryto Glacier and other maritime glaciers. $Q_{R}$ : the net radiation, $Q_{H}$ : the sensible heat flux and $Q_{E}$ : the latent heat flux.

Table 2 The influences of the type of formula and inputs on accuracy of simulation of ablation rate at KK1. Equation 5: model type of Hock (1999), Equation 10: RT model in this paper, I: potential direct solar radiation, R: measured global radiation, $\mathrm{d}$ : daily mean air temperature, h: hourly air temperature, $r^{2}$ and RSS: the coefficient of determination of the relationship with and the residual sum of squares from the ablation rate obtained by the heat balance method. 


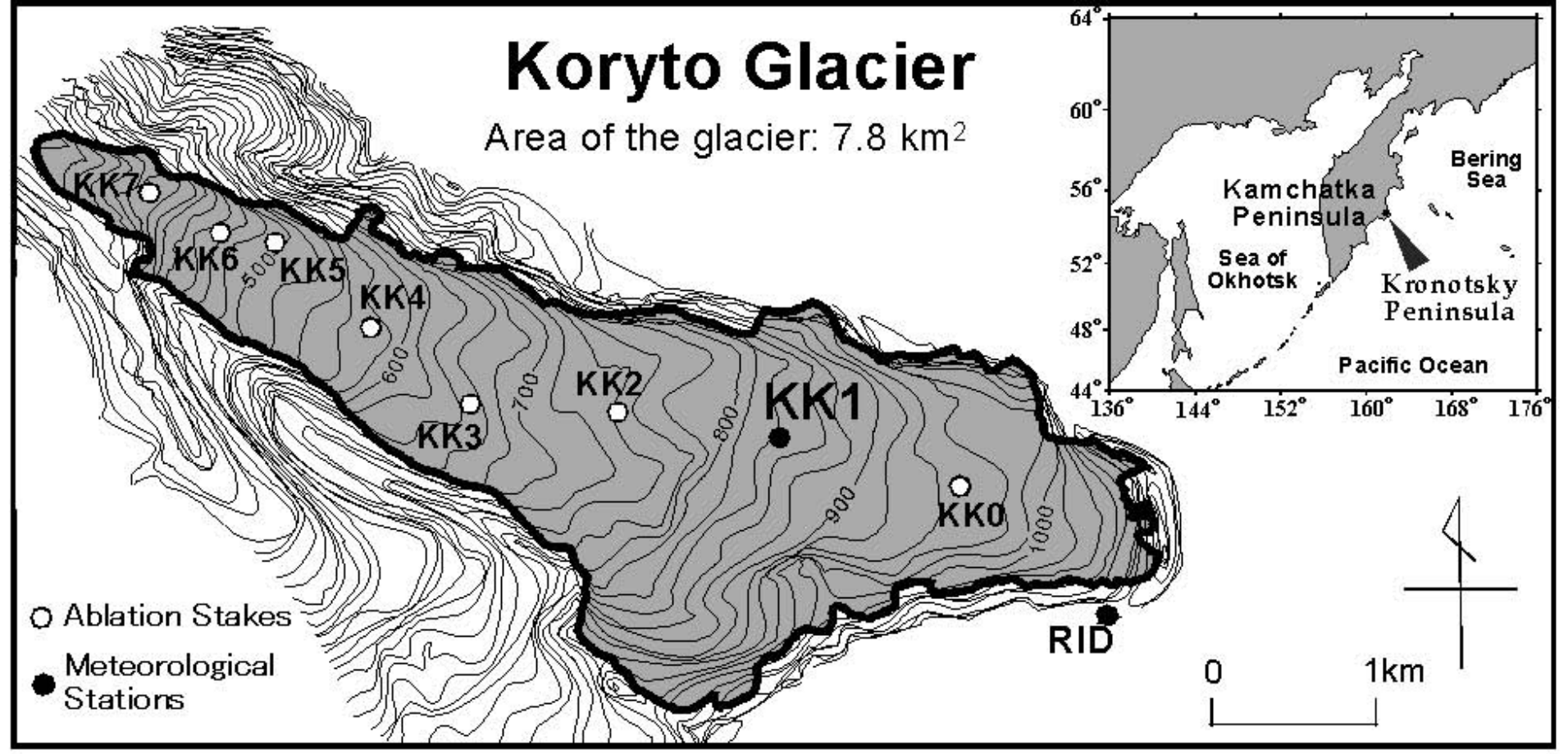




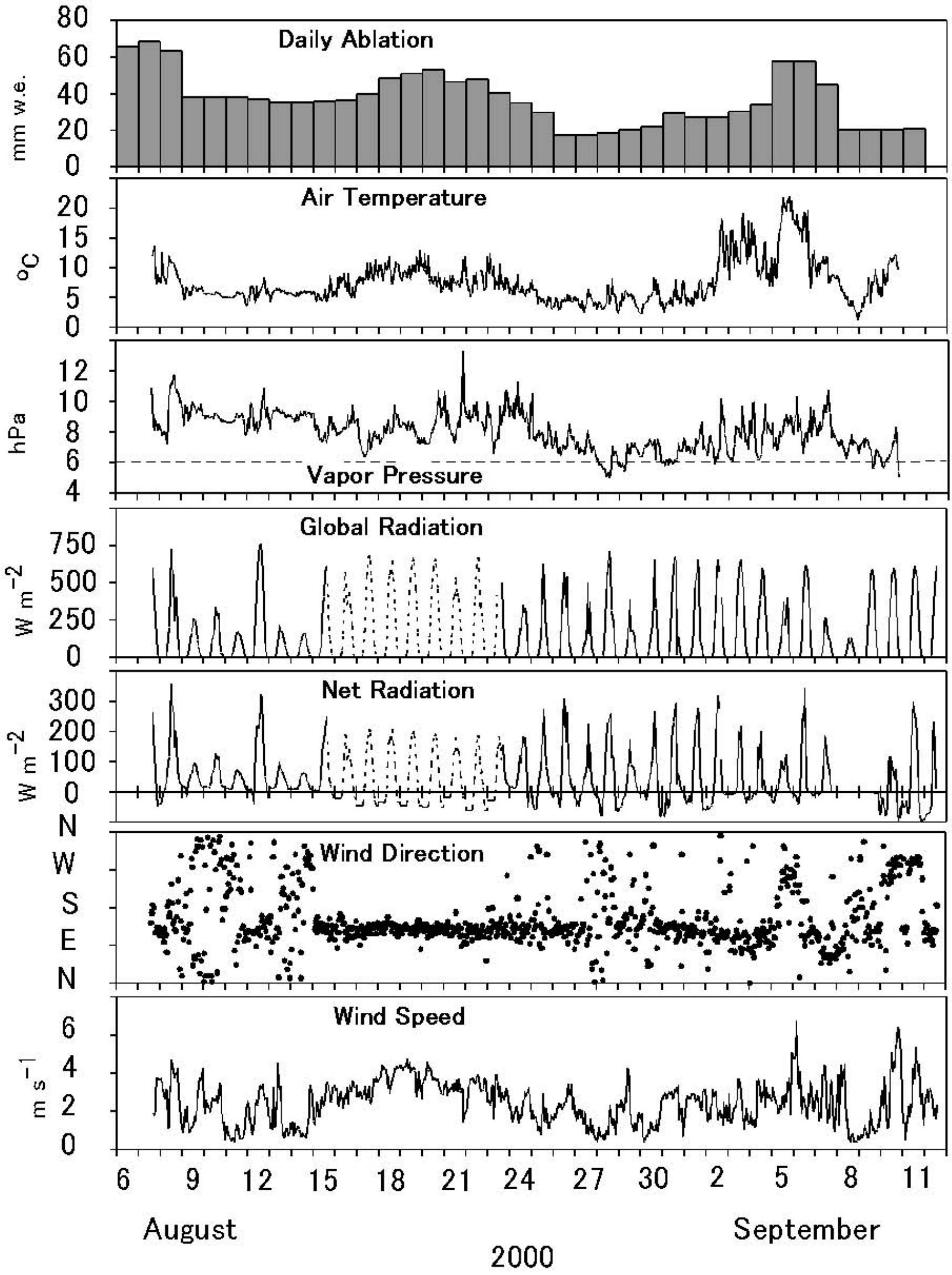




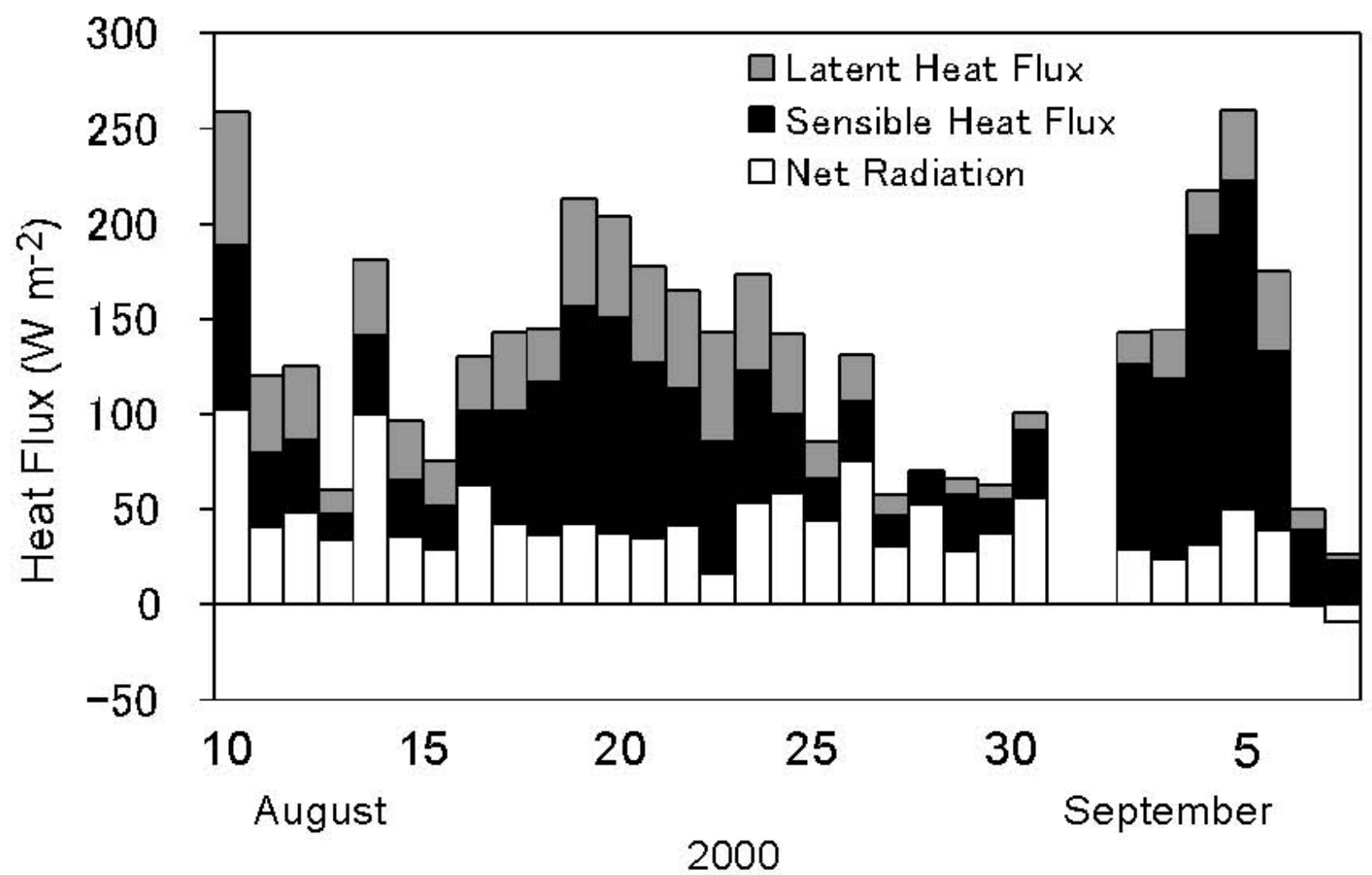




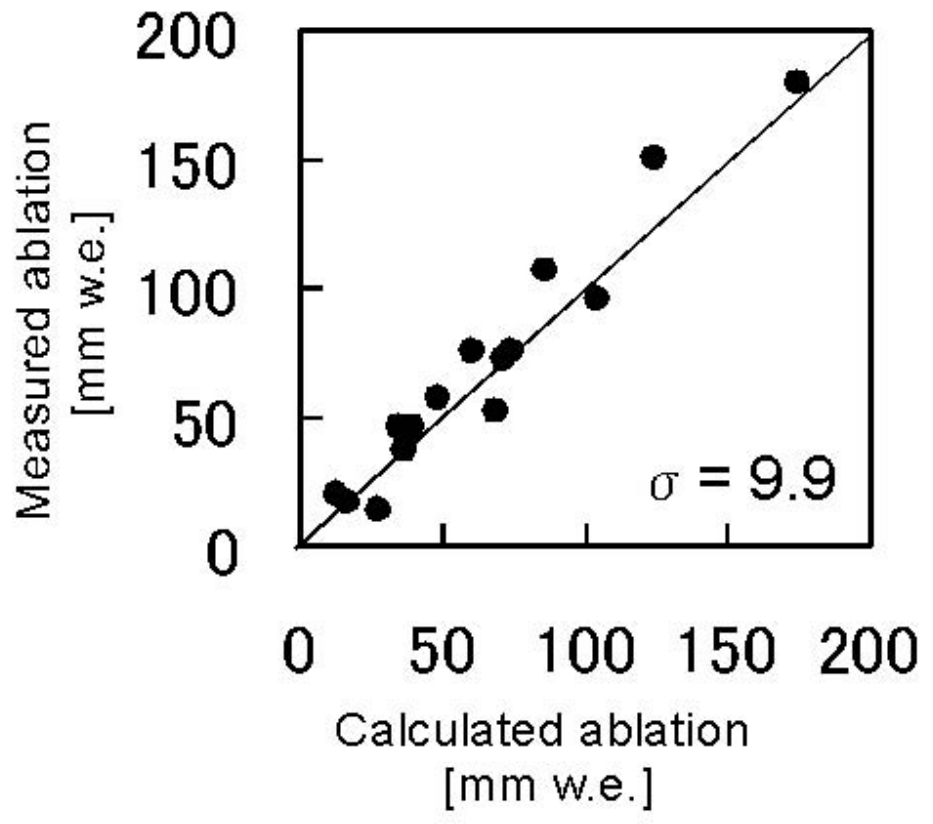




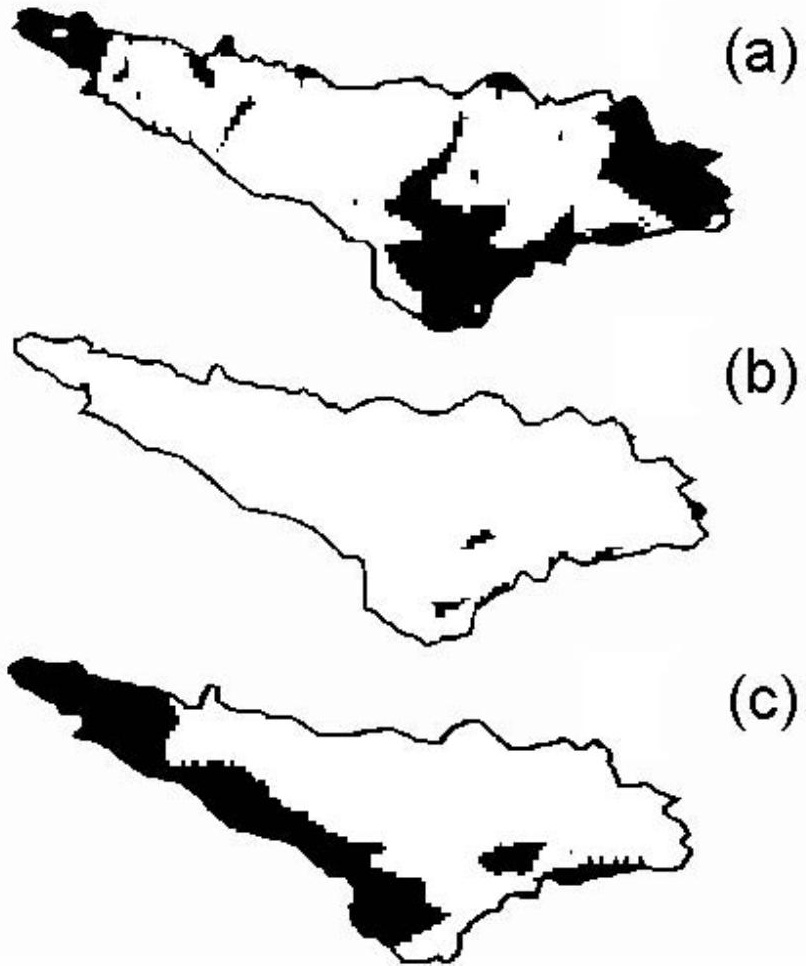


a)
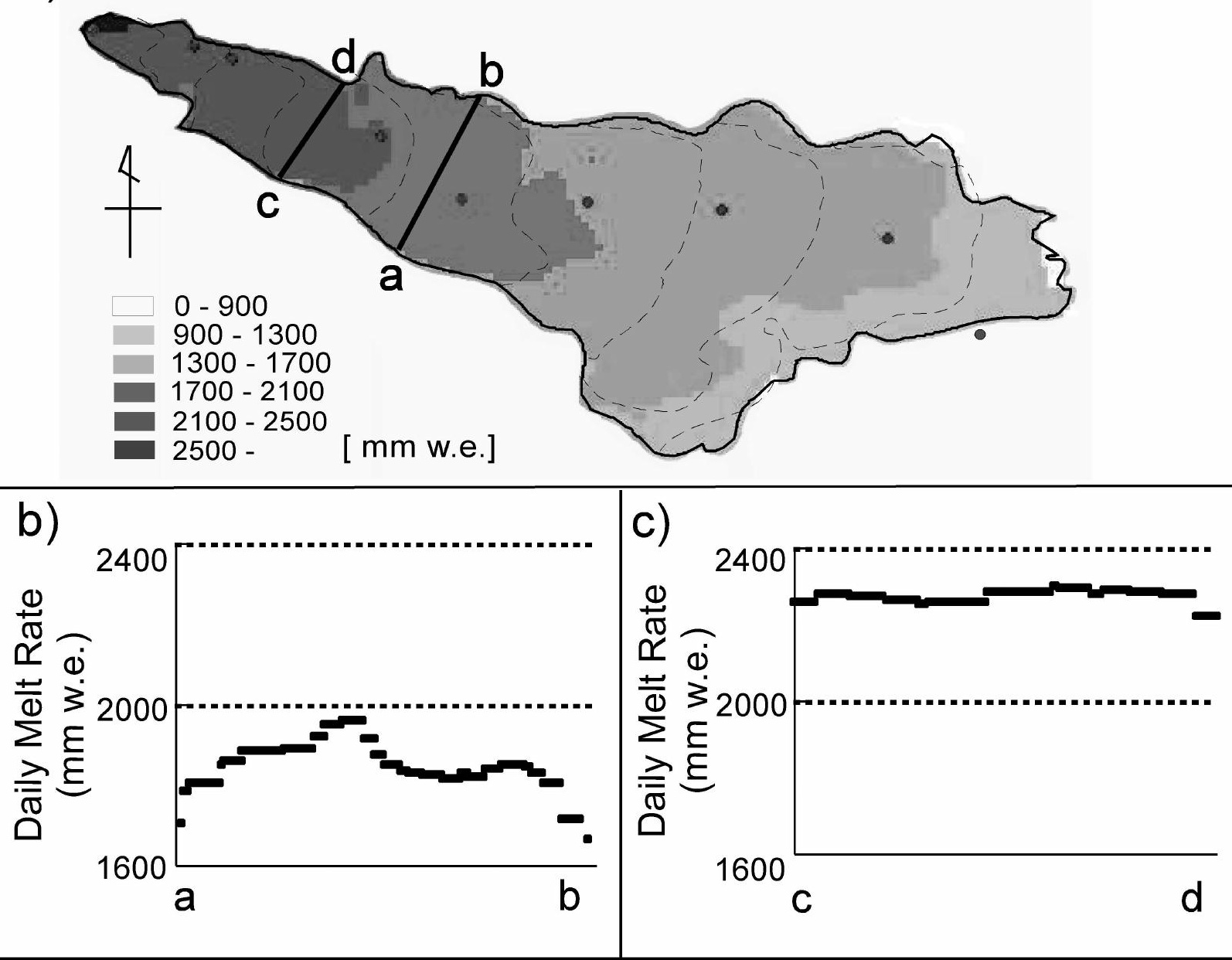


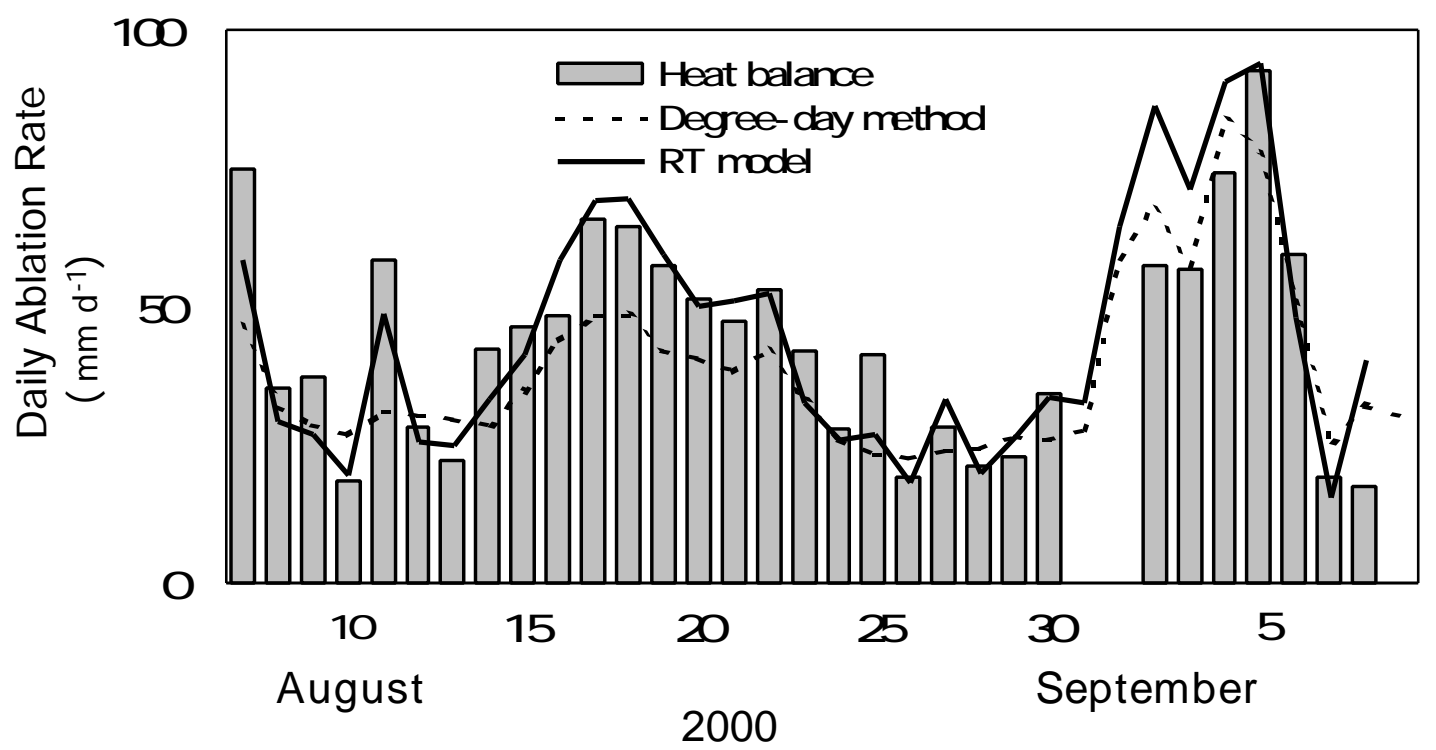

